\title{
Self-efficacy perceived in academic behaviors in university students of 'health' and 'social' sciences
}

\author{
Yunuen Rangel Ledezma ${ }^{1}$, Humberto Blanco Vega ${ }^{1}$, Judith Margarita Rodríguez-Villalobos ${ }^{1}$, \\ Isabel Castillo Fernández ${ }^{2}$, Jeanette López-Walle ${ }^{3}$ \\ ${ }^{1}$ Faculty of Physical Culture Sciences, Autonomous University of Chihuahua, México \\ ${ }^{2}$ Faculty of Psychology, University of Valencia, Spain \\ ${ }^{3}$ Faculty of Sport Organization, Autonomous University of Nuevo León, México
}

\section{Email address:}

yunuen_r@hotmail.com (Y. Rangel), hblanco@uach.mx (H. Blanco), jurodrig@uach.mx (J. M. Rodríguez-Villalobos), isabel.castillo@uv.es (I. Castillo),jmlopezw@yahoo.com.mx (J. López-Walle)

\section{To cite this article:}

Yunuen Rangel Ledezma, Humberto Blanco Vega, Judith Margarita Rodríguez-Villalobos, Isabel Castillo Fernández, Jeanette López-Walle. Self-Efficacy Perceived in Academic Behaviors in University Students of 'Health' and 'Social' Sciences. Science Journal of Education. Vol. 3, No. 1, 2015, pp. 6-10. doi: 10.11648/j.sjedu.20150301.12

\begin{abstract}
The aim of this present study consisted in comparing the profiles of the academic Self-efficacy perceived in 'Social' and 'Health' Sciences University students. The total sample was 1113 subjects; 524 from Health Sciences and 589 from Social Sciences, with an average age of 18.20 years $(\mathrm{DS}=0.72)$ and 18.24 years $(\mathrm{DS}=0.74)$ respectively. The approach adopted in this research was framed into a quantitative approach with a descriptive design, survey type. The results show that the perceived self-efficacy profiles are very similar among 'Social' and 'Health' Sciences students. And behaviors related to 'Communication' factor, represent an opportunity area for University students in their first year. Future studies should replicate these findings with larger samples.
\end{abstract}

Keywords: Student's Beliefs, Individual Differences, Higher Education, Academic Performance, Student Characteristics

\section{Introduction}

In the Educational Context it has always existed a permanent interest to understand the cognitive and behavioral factors favoring or obstructing student performance in the academic activities and how the this performance relates to the student's integral development. In the psychology area, specifically, the term self-efficacy has received special attention and has also generated important research progress, which has contributed to the improvement of the pedagogical and teaching practices[1]. Empirical research has demonstrated in a wide way that self-efficacy is more predictive of the academic performance than other cognitive variables [2], it also can predict a posterior success $[3,4]$ and that it is an important cognitive meditator of competence and performance [5] as soon as it favors the cognitive processes $[6,7]$.

Therefore, people's beliefs about themselves represent a basic factor achieving their activities, or taking decisions during their lifetime. The higher self-efficacy is perceived, the higher will be the degree of effort made and the persistence of achievement of their proposed goal; this is very important for success in a person who is in a learning process [3, 4].

Self-motivation encourages humans to understand specific behaviors related to achievements to reach. But it is not enough to clearly know all we want to achieve neither the best way to obtain it. It is also not enough to be able to; it is necessary to believe of being capable of using personal capacities and skills in different circumstances. Peoples' perception about their own efficacy becomes a fundamental requirement to develop with success all actions conducted to achieving personal goals. Such Self-perfection, denominated self-efficacy, has a strong influence while choosing tasks and abilities in the effort and perseverance of people when facing specific challenges even in emotional relationships they experiment in difficult situations [1, 8, 9]. In other words, beliefs related to self-efficacy represent a cognitive mechanism between knowledge, actions and, what determines it among other variables, and the success of self-actions [1, 10-12].

This is mainly a descriptive type study which tries to 
compare the profiles of Academic Self-efficacy perceived by University students of 'Social' and 'Health' Sciences; taking in consideration that beliefs about self-efficacy affect human behavior in different ways: (a) Influences students choices and their behavior to follow them: (b) motivates the students for skills where he feels competent and confident, while this helps the student to avoid those skills where he doesn't feel this way: (c) determines how many effort will the student need to accomplish his task, and (d) predicts how long will it take to accomplish the task and how he will recuperate while facing adverse circumstances. That is why; subjects with high sense of self-efficacy will increase their socio-cognitive functioning in a lot of domains, confronting difficult tasks perceiving them as changeable rather than risky.

Furthermore, they will be in activities with a high interest and commitment putting a great effort in what they are doing, increasing this effort when confronting difficulties and obstacles. A high perceived efficacy increases goals driven, reduces stress and diminishes vulnerability to depression [3]. Therefore, beliefs about efficacy contribute to human achievements and increase of motivation [13] that influence in a positive way in what people think, feel and do.

This study pretends as an applied research to provide information that results into an higher quality educative practice in the context of attention to diversity; contributing to the pedagogical knowledge clarifying the factors which form a school performance model and an integral human development, under the premise of improving their perception of being capable, and that, the person who is 'learning' is considered a valuable educational goal, in the implied assumption that its empowerment, will help as a mean to improve other results such as the academic success and a self-esteem; considering that the continuous failing conscience reduces success expectations and does not contribute to neither learning nor personal development. This present study contributes with evidences and information, which enables educative intervention into an educative perspective of attention to diversity in the classroom.

\section{Methodology}

\subsection{Participants}

A sample of 524 students from Health Sciences participated in this present study. 202 (38.5\%) women and $322(61.5 \%)$ man aged 17 and 20 years $(M=18.20$ and $S D=0.72)$.

A sample of 589 students from Social Sciences participated in this present study. 376 (63.8\%) women and 213 (36.2) man, aged 17 and 20 years $(M=18.24$ and $\mathrm{SD}=0.74)$.

Both samples were obtained through unit (quota) sampling, trying to cover a representative data of both areas Health and Social Sciences offered at Autonomus University of Chihuahua.

\subsection{Instrument}

The academic behavior Self-esteem Scale designed by [14] is a survey Likert type, computer-assisted, with 13 items related to academic behaviors; where the interviewed answers in a scale from 0 to 10 the frequency the student currently, in an ideal form if he tries to change, would do or manifest and action. And then from the students answers obtain five indices:

1. Currently perceived Self-efficacy.- obtained from the answers of a current scenario.

2. Desired Self-efficacy.- obtained from the answers of a current scenario.

3. Future Reachable Self-efficacy.- obtained from the answers of an scenario of change.

4. Degree of dissatisfaction or perceived self-efficacy dissonance.- obtained through the difference between index 2 and 1 (less current ideal).

5. Improvement possibility in perceived self-efficacy.obtained through the difference between index 3 and 1 (less current change).

The structure of three factors: Communication, attention and excellence, for this scale (Table1), based on statistical and substantive criteria have demonstrated appropriate indicators of adjustment, flexibility and validity [14-16].

Table 1. Academic Behavior Self-efficacy Scale Items, grouped by factor.

\begin{tabular}{ll}
\hline Factor & Ítem \\
\hline Comunicación & 4 Express my ideas clearly. \\
& 5 I make pertinent comments and contributions \\
& 12 In case of disagreement I am able to have a conversation with my professors. \\
& 13 I feel fine with my own development when I speak in front of a class or group of people. \\
& 2 I listen with attention when the professor clarifies a doubt to a classmate \\
& 3 I listen with attention my classmates' questions and opinions \\
& 6 I pay attention when professors teach their class \\
Attention & 7 I pay attention when a classmate has an exposition in class \\
& 11 I listen with attention my professor's questions and comments \\
& 1 I do the tasks assigned to me \\
& 8 I prepare myself for my exams based on my class notes, textbook, and additional readings \\
& 9 I hand in on time the works assigned to me \\
& 10 I am responsible for my class attendance \\
\hline
\end{tabular}

This type of survey was chosen because it is easy to make and apply; besides, it also provides a good base for a first subjects ordering in the characteristic they are been measured; in our case, self-efficacy $[17,18]$. On the other hand, participants are used to the scale 0 to 10 . They have been measured this way by Mexico's Educational System; Reference [19] report that the type of scale with Spanish population and reference [14] with Mexican University Students. 


\subsection{Design}

Descriptive, non-experimental and transversal, sociological type. There is no intentional, random assignation or manipulation, and data obtained is investigated in a unique time, with the goal of describing variables and analyzing its incidence or interrelation in an specific moment [20].

\subsubsection{Explicative Variable}

Discipline. With the following values: 'Health' and 'Social' Sciences.

\subsubsection{Answering Variables:}

Score of the five indices above described in every one of the three factors: Communication, Attention and Excellence.

\subsection{Procedures}

Students of the first year at the 'Social' and 'Health' Sciences areas at the Autonomous University of Chihuahua were invited to participate; the ones who accepted the invitation signed a consent letter. Then, the instrument explained above was applied through a personal computer using the instrument administrator from the module of scales editor, version 2.0 in a session of about 30 minutes in the computer labs correspondent to each participating academic unit. At the beginning of each session students were given a brief introduction on the importance of the study and how to access to the instrument; instructions of how to answer were displayed on the first computer screens, before the first instrument item. At the end of the session students were thanked for their contribution to the study.

Once the instrument was applied, data was collected by the results generator module of scales editor, version 2.0 [21]."

\subsection{Data Analysis}

To compare the results obtained in men and women a variance analysis was used among groups (ANOVA), after verifying the data as they met the requirements of the normal statistical criterion (Shapiro - Wilks testing).

\section{Results}

\subsection{Self-Efficacy Perceived Currently}

According to the results obtained, students from 'Health Sciences' perceived themselves significantly better than 'Social Sciences' students in 'Attention' factor. $F(1,1111)=$ $9.770, \mathrm{p}<.01$ and without significant differences in 'communication' (Figure 1).

\subsection{Desired Self-Efficacy}

According to the obtained results, students from 'Health Sciences' perceived themselves significantly with a higher need of being more self-effective than students from 'Social Sciences' in the 'Attention' factor $\mathrm{F}(1,1111)=11.688, \mathrm{p}<.01$ and without significant differences in Communication and Excellence (Figure 2).

\subsection{Future Reachable Self-Efficacy}

According to the results obtained, there were no significant differences in any of the studied factors as to the possibility of being more self-efficient (Figure 3 ).

\subsection{Degree of Dissatisfaction or Perceived Self-Efficacy Dissonance}

According to the obtained results, there were no significant differences in any of the studied factors as to the dissatisfaction of dissonance shown (Figure 4).

\subsection{Improvement Possibility in Perceived Self-Efficacy}

According to the obtained results, students of 'Social Sciences' show a higher possibility to improve their perception of self-efficacy than students from 'Health sciences' in 'Action' factor $\mathrm{F}(1,1111)=8.918, \mathrm{p}<.01$ and without significant differences in 'Communication' and 'Excellence' (Figure 5).

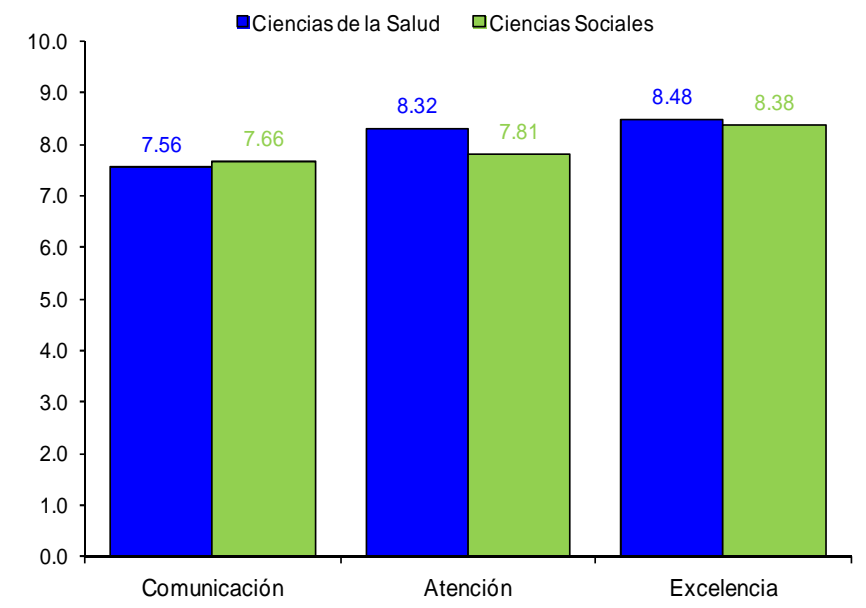

Figure 1. Currently Perceived Self-efficacy average in each one of the factors according to 'Discipline'variable.

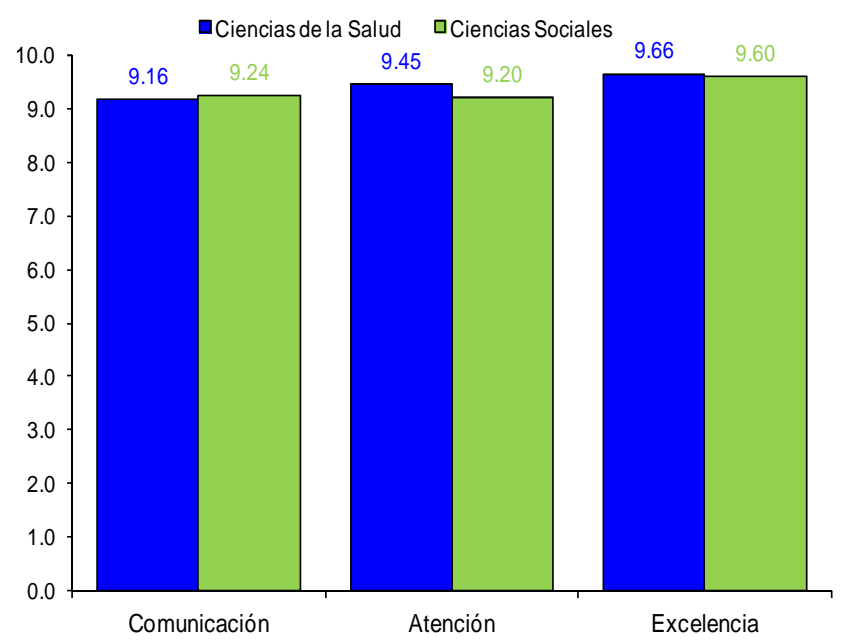

Figure 2. Desired Self-efficacy average of each one of the factors according to 'Discipline'variable 


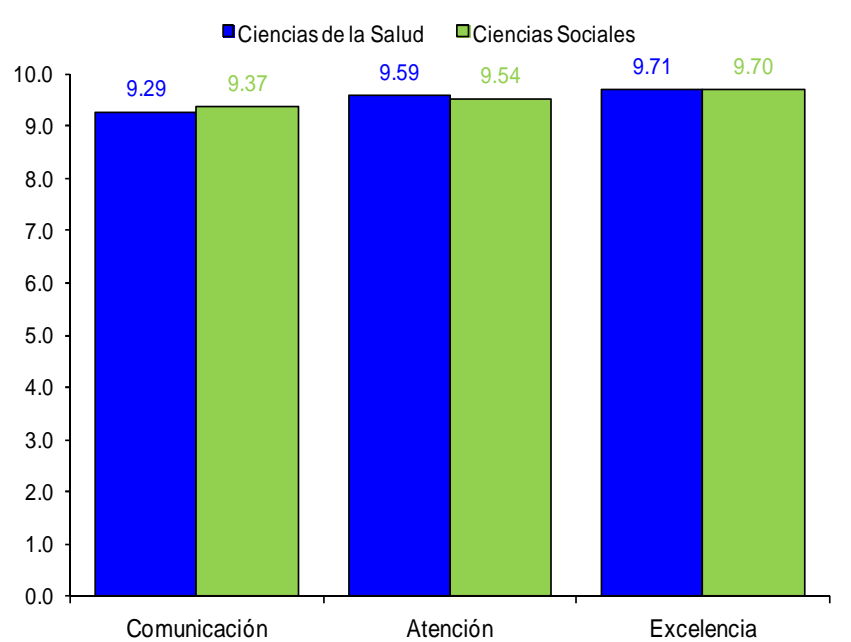

Figure 3. Future Reachable Self-efficacy in each one of the factors according to 'Discipline' variable.

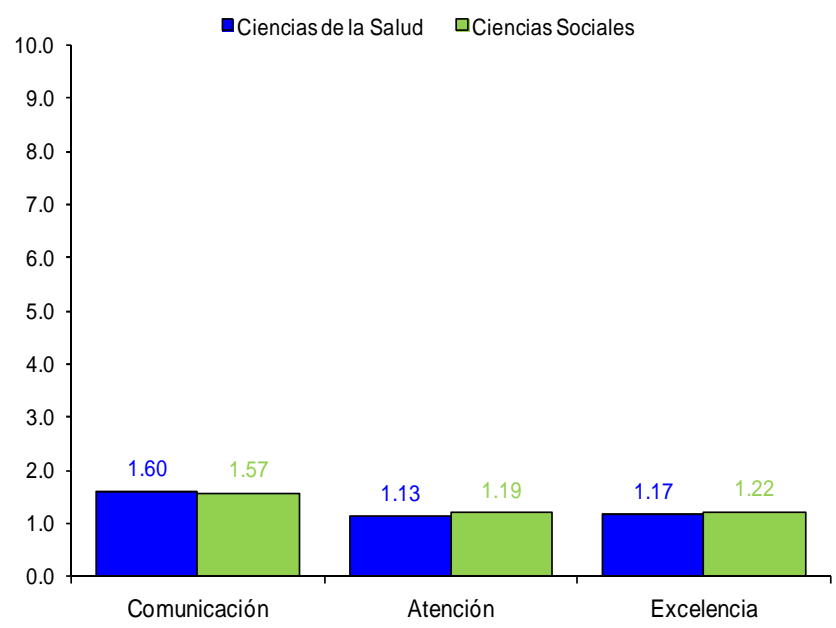

Figure 4. Dissatisfaction or Dissonance Average of perceived Self-efficacy In each one of the factors according to 'Discipline' variable.

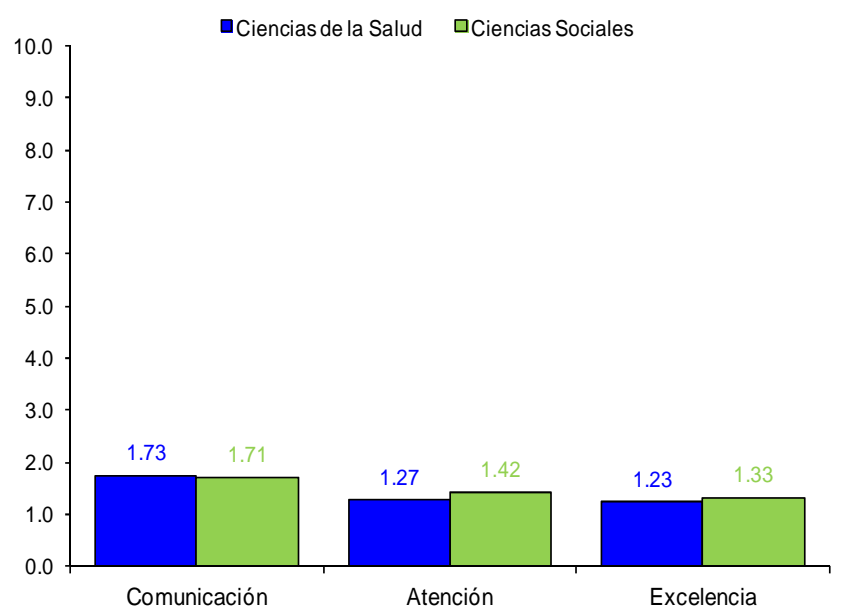

Figure 5. Improvement possibility in perceived self-efficacy of each one of the factors according to 'Discipline' variable.

\section{Discussion and Conclusions}

'Attention' factor: Listen carefully when the professor clarifies a doubt, a question or an opinion to the classmates; pay attention when professors or classmates teach a class, and listen carefully to the professor's questions and comments; 'Health Science' students perceive themselves as more self-efficient, and at the same time with a higher need of being more self-efficient than students from 'Social Sciences'. These were the only a differences found while comparing self-efficacy profiles from Health Sciences students with the profiles of self-efficacy from students of Social Sciences. In relation to the indicators of the studied factors (Attention, Communication and Excellence), it can be assumed that perceived self-efficacy in academic behaviors are very similar among them, this result agrees with those reported by a very similar study of self-efficacy perceived in University students; This is a very encouraging result because students of 'Health' and 'Social' Sciences arrive to the University with the 'same quality', this is specifically about academic Self-efficacy. Furthermore, in relation to 'Communication' factor, this is, expressing ideas with clarity, make comments and pertinent opinions, when disagree being able to make a conversation with their professors and feel fine with their performance when talking in front of a class or group of people. Even when there are no significant differences in the perceived self-efficacy among students from 'Health' and 'Social' Sciences; it is important to emphasize that from the three studied factors (Attention, Communication and Excellence) is the factor where the students in general perceived themselves as less self-efficient; with less need of being more self-efficient and with the possibility of being more self-efficient, showing a higher degree of dissatisfaction or dissonance in their own perceived self-efficacy. Conclusion that in general agrees with the results of a similar study about perceived self-efficacy in academic behaviors in university women, where [4], using the same measuring instrument, found that university women report in general, lower levels of academic self-efficacy in the 'communication factor' than in the factors of 'attention' and 'excellence'; Behaviors related to the 'communication' factor represent an opportunity area for University women as well as University women at the first year. Besides, that the profiles of current, desired and reachable self-efficacy correspond among themselves, (to a higher perceived self-efficacy, higher desire and higher possibilities of being efficient) aloud to conclude that if it is possible to improve any of them, the others will improve too.

Finally, taking in consideration that the empirical study has demonstrates in a wide form that self-efficacy results to be more predictive of academic performance than other cognitive variables [2], which predicts a further success [3, 4] and that is an important cognitive mediator of competence and performance [5] as it favors the cognitive processes [6, 7] we conclude to improve the perception of 'being able to' in the person that is learning and how it is a valuable educational goal, under the implicit assumption that its potentiality will help as mean to help other results, such as academic achievement and self-esteem. Considering that the continuous conscience of failure reduces success expectations and does not help 'learning' or 'personal development'.

This study is part of a project funded by the "Secretaría de 
Educación Pública - Subsecretaría de Educación SuperiorDirección General de Educación Superior Universitaria de México" [Mexican Ministry of Education-Department of Higher Education-General Directorate of the University Education] (OF-13-6894).Additionally, the fourth author is supported by a grant from the National Council of Science and Technology of Mexico (Conacyt).

\section{References}

[1] Pérez, E., C. Lescano, D. Heredia, P. Zalazar, L. Furlám and M. Martínez, Desarrollo y análisis psicométricos de un inventario de autoeficacia para inteligencias múltiples en niños argentinos Psicoperspectivas, 2011. 10(1): p. 169-189.

[2] Bandura, A., Self-efficacy mechanism inhuman agency. American Psychologist, 1982. 37(2): p. 122-147.

[3] Bandura, A. Self-efficacy: The exercise of Control. New York: Freeman.1997.

[4] Ornelas, M., H. Blanco, G. Gastélum and A. Chávez, Autoeficacia Percibida en la conducta Académica de Estudiantes Universitarias. Formación Universitaria, 2012. 5(2): p. 17-26.

[5] Vera, M., M. Salanova and B. Martín-del-Río, Self-efficacy among university faculty: how to develop an adjusted scale. Anales de Psicología, 2011. 27(3): p. 800-807.

[6] Carbonero, M. Á. and E. Merino, Autoeficacia y madurez vocacional. Psicothema, 2008. 16(2): p. 229-234.

[7] Ornelas, M., H. Blanco, J. M. Rodríguez and F. J. Flores, Análisis psicométrico de la escala autoeficacia en conductas de cuidado de la salud física en universitarios de primer ingreso. Formación Universitaria, 2011. 4(6): p. 21-34.

[8] León-Rubio, J. M., F. J. Cantero and J. M. León-Pérez, Diferencias del rol desempeñado por la autoeficacia en el burnout percibido por el personal universitario en función de las condiciones de trabajo. Anales de Psicología, 2011. 27(2): p. $518-526$.

[9] Wolters, C., Advancing achievement goal theory: using goal structures and goal orientations to predict students 'motivation, cognition and achievement. Journal of Educational Psychology, 2004. 96(2): p. 236-250.

[10] Castañeda, S., M. d. L. Pineda, E. Gutiérrez, N. Romero and E. Peñalosa, Construcción de instrumentos de estrategias de estudio, autorregulación y epistemología personal. Validación de constructo. Revista Mexicana de Psicología, 2010. 27(1): p. 77-85.
[11] Sansinenea, E., L. Gil, A. Agirrezabal, M. Larrañaga, G. Ortiz, J. F. Valencia and M. J. Fuster, Autoconcordancia y autoeficacia en los objetivos personales: ¿Cuál es su aportación al bienestar? Anales de Psicología, 2008. 24(1): p. 121-128.

[12] Zimmerman, B. and A. Kitsantas, Homework practice and academic achievement. The mediating role of self-efficacy and perceived responsibility beliefs. Contemporary Educational Psychology, 2005. 30(4): p. 397-417.

[13] Bandura, A. Exercise of personal agency throught the self-efficacy mechanism, in Self-efficacy: thought control of action, R. Schwarzer, Editor., Hemisphere: Washington D C. 1992; p. 3-38.

[14] Blanco, H., M. Martínez, M. d. C. Zueck and G. Gastélum, Análisis psicométrico de la escala autoeficacia en conductas académicas en universitarios de primer ingreso. Actualidades Investigativas en Educación, 2011. 11(3): p. 1-27.

[15] Elosua, P. and B. D. Zumbo, Coeficientes de fiabilidad para escalas de respuesta categórica ordenadas. Psicothema, 2008. 20(4): p. 896-901.

[16] Thompson, B. Exploratory and Confirmatory Factor Analysis. Understanding concepts and applications. . Washington, D C: American Psychological Association.2004.

[17] Nunnally, J. C. and I. H. Bernstein. Teoría Psicométrica. México: McGraw-Hill.1995.

[18] Raviolo, A., P. Ramirez, E. A. López and A. Aguilar, Concepciones sobre el conocimiento y los modelos científicos: un estudio preliminar. Formación Universitaria, 2010. 3(5): p. 29-36.

[19] Viciana, J., E. M. Cervelló and J. Ramírez, Effects of manipulating positive and negative feedback on goal orientation, perceived motivational climate, satisfaction, task choice, perception of ability, and attitude to physical education lessons. Perceptual and motor skills, 2007. 105(1): p. 67-82.

[20] Hernández, R., C. Fernández and P. Baptista. Metodología de la investigación. México: McGraw- Hill.2010.

[21] Blanco, H., M. Ornelas, J. L. Tristán, A. Cocca, D. Mayorga-Vega, J. López-Walle and J. Viciana, Editor for creating and applying computerise surveys. Procedia Social and Behavioral Sciences, 2013. 106: p. 935-940. 